Article

\title{
The Sustainability of Teaching Personification in Language Education: A Qualitative Analysis Using Kwang-Chung Yu's Free Verse
}

\section{Hsin-Chi Ko}

Department of Mass Communication and Language Education Centre, Chang Jung Christian University, Tainan City 71101, Taiwan; hsin899@gmail.com; Tel.: +886-6-278-5123 (ext. 5016)

Received: 12 August 2018; Accepted: 26 September 2018; Published: 30 September 2018

\begin{abstract}
Many scholars consider Kwang-Chung Yu (1928-2017) a prominent practitioner of free verse. The poetic quality of his work shows considerable ingenuity, and a key feature is his use of personification to create a humorous style. Collection of Humorous Free Verses by Kwang-Chung Yu contains the most representative examples of his work. As there are no existing studies on how Yu's personification technique could be used for language education, the present study takes a qualitative approach to explore this topic. Of the verses featured in the collection, $88 \%$ of them use personification, and 102 personified themes were found overall. The discussion consists of four parts that serve as references for language education: (1) an analysis of examples representing the six categories of personified themes, (2) eight major reflection shortcuts for personification; (3) the association and application of eight types of situations for personification; and (4) a review of an online questionnaire and its positive results. The concluding section summarises Yu's use of personification and presents a comprehensive model of personification for language education based on a pragmatic analysis. This model is a study of a master poet and is sure to be of interest to anyone who wants to know how personification techniques are crafted.
\end{abstract}

Keywords: pragmatic analysis; language education; personification; free verse; Kwang-Chung $\mathrm{Yu}$; sustainability

\section{Introduction}

In recent years, academic research in several countries has been aimed at promoting the applicability and popularisation of specialised knowledge. The field of language education especially maintains practicality as one of the principal aims of research. In other words, if research results are presented in a confusing, mystifying way that does not highlight the benefits of practical application, then the findings have little value regardless of how robust the research methods were. This study keeps both practicality and applicability at the forefront by analysing the linguistic structure behind one poet's use of personification. The researcher hopes readers will come to understand the poet's personification technique through the lens of language education and that the results will serve as a reference point for readers who want to improve their literary and creative skills.

Since ancient China, classical writers have often used personification. The effects of their skilful personification have not only injected life into literature but also created an artistic aesthetic in language use. Outside of Asia, English dictionaries spanning from the fifth to the eighteenth centuries have provided descriptions of personification as it is used in the literary arts. Thus, personification is a sustainable topic for modern language education. The current trend in language education is to enhance a student's writing skills to stimulate individual critical thinking and creativity. The goal of this study is to help readers improve their writing skills through the use of personification. This objective 
will be accomplished by first completing an in-depth analysis of Kwang-Chung Yu's personification technique in a collection of his free verse [1] and then discussing how Yu's approaches can be practically applied in any writing featuring personification.

$\mathrm{Yu}$ is considered one of the most famous contemporary literary authors in the Chinese region. Because of his outstanding achievements in Chinese free verse, he is also held as one of the greatest poets in contemporary poetry circles [2]. Many scholars have studied the distinguishing features of $\mathrm{Yu}_{\mathrm{u}} \mathrm{s}$ free verse and found the essence of classical literature in the lines of his work [3]. However, the aesthetics of classical poetry are diverse, and one style in particular pertains to thoughts on people. Chen [4] has suggested that Yu's free verse provides new interpretations and representations of historical figures.

Chou [5] shared the same viewpoint and argued more specifically that Yu extracted the essence of Po Lee's works and integrated it into his own verses to create new lives. From the perspective of quoting historical literature, Chang [6] asserted that Yu's verses integrates myths and extends the soul-searching process in life. It is thus evident that Yu's free verse not only features the aesthetics and art of classical poetry, but also depicts life issues using insights drawn from the perspective of people's innermost feelings and thoughts. This means Yu's poetry is rich in deep experiences and feelings.

Classical awareness can be found in Yu's free verse [4], which falls in line with the trend of free verse fighting against established traditions in Taiwanese literary circles during Yu's time [6]. His concept of classical awareness is not invariable and conservative thinking. It is about being active, carrying on past heritage and opening it up to the future, and developing new conceptual understandings from classical beliefs. Yu's approach to classical awareness has been recognised by scholars. For example, Ting [7] stated that classical inheritance and innovation can both be found in Yu's free verse since he transformed the titles, contents, sentences, allusions, techniques, and styles of classical poetry into free verse to create new techniques, styles, and artistic conceptions in this poetic form.

Most scholars hold a positive attitude towards the classical features of Yu's free verse. However, there are a few scholars who think differently. According to Wei [8], because the focus of Yu's free verse is on artistic conceptions of classical poetry, the poetic quality of his work is prosified, the free verse forms are limited, and the linguistic effects of the verses are reduced. As a result, Yu's verses can hardly leave readers with a rich aftertaste. Moreover, there exists the assertion that Yu's literary works are Europeanised [9].

However, the modern academic community stresses cross-field practice, which is one characteristic of Yu's free verse. $\mathrm{Xu}$ [10] believed that the artistic viewpoints found in Yu's literary works are associated with modern painting. Yu took both words and images into consideration when writing free verse. Thus, the traditional practice of expressing emotions can be seen in his contemporary free verse, which reconstructs such expressions with a more mature, modern aesthetic [11]. This is why Yu's free verse has a diverse quality, featuring elements of classical, contemporary, Eastern, and Western literature. In addition, Yu's poetry uses a broad lens where the art of painting lies under his linguistic presentation.

Yu's free verse is highly praised mainly because of his capability in managing words. For example, some scholars have studied his translations and noted his flexible use of words [12,13]. Yu could translate intricate and obscure words into terms the general public would understand by focusing on capturing the meaning of the original text and popularising it [14]. Scholars such as Chou [5] have also studied the structure behind Yu's use of figures of speech and highlighted his great expressive techniques.

Another key feature of Yu's free verse is the integration of emotion into the artistic conception of the themes underlying the verses. For example, Yu's poetry features rich content in terms of the feelings associated with the word rain $[15,16]$ and with regard to his lyrical descriptions of life experiences [17]. Meanwhile, Huang [18] has suggested that Yu's free verse shows a kind of homesickness for his own home town. Liu [19] argued that Yu's feelings of homesickness can be categorised into three groups 
based on distinct time periods. Furthermore, Yu's strong emotions are often associated with solar terms related to the seasons, specific moments of the day such as sunrise and sunset [20], and history. For example, Yu's "Terracotta Warrior" expresses historical sentiments vividly based on the historical issues that were integrated into the work. Yu's free verse reveals his feelings towards a wide range of topics, including other people, his home town, the land, and history.

From the perspective of literary communication, various scholars have recognised the impact Yu's poetry has had on the aesthetics and art of free verse from a historical perspective [21]. Yu created exquisite linguistic and artistic conceptions and aesthetic value for free verse by integrating different cultural backgrounds from throughout the ages and blending them with contemporary meanings in his works while considering both the ancient and modern essences of language aesthetics. One scholar from Hong Kong has described Kwang-Chung Yu as a "magician of language" [22]. The quantity and quality of Yu's body of work is certainly considerable, and many scholars deem him one of the greatest modern writers.

Using Collection of Humorous Free Verses by Kwang-Chung Yu, the researcher has classified Yu's free verse into five categories: (1) careful observations based on the senses with vivid descriptions of dynamic scenes and objects; (2) love of nature and cultural environments; (3) vivid and imaginative descriptive techniques; (4) deep, sensitive illustrations of the human psychology that kindle feelings and emotions; and (5) novel linguistic techniques to create new artistic conceptions. All five groups exhibit expressive characteristics that can be translated into tools for language education.

After reviewing the direction of recent research in linguistics, the researcher found that it has been closely tied to the features enumerated above. For example, some studies have involved detailed descriptions of natural phenomena based on sense perception, which creates a literary aesthetic that touches readers' hearts [23-27]. Studies completed in this vein relate to the first feature of careful observations based on the senses. Other studies have explored how Yu's work reminds people about the dignity of life and encourages them to care about others based on lessons from their cultures, customs, geography, and experiences $[25,28,29]$. These themes fall within the second category of loving nature and cultural environments.

Still other studies have looked at how Yu's free verse makes connections with readers' imaginations by using literature to investigate the psychological space within us [30-33]. These studies touch on the third feature of vivid and imaginative descriptive techniques. Meanwhile, studies that discuss sensibility as a source of motivation for literary creativity dig into how literary works are often inspired by the author's feelings and emotions, a fact that regularly appeals to readers [34-37]. Studies on this topic address the fourth feature of providing deep, sensitive illustrations of the human psychology.

Finally, a number of studies have considered the vitality of words and how techniques employed by playwrights, among others, can create new and striking artistic conceptions that resonate with audiences [38-41]. These studies address the fifth category of novel linguistic techniques. Whatever its final form, literature is a type of art [31], and Yu's free verse brims with artistry. Thus, studying Collection of Humorous Free Verses by Kwang-Chung Yu [1] covers issues currently of interest in the field of language education. It is hoped that this research will help readers understand the personification technique Yu applied in his poetry and will ultimately strengthen the applicability of research on creative skills to language education. To clarify for readers the usage and understanding of personification as a literary concept, 18 dictionary definitions of personification are provided in Table 1 . 
Table 1. Eighteen dictionary definitions of personification.

\begin{tabular}{|c|c|c|}
\hline No. & Definition & Source \\
\hline 1 & "The act of regarding as a person" & [42] (p. 1077) \\
\hline 2 & "Representing as a person" & [43] (p. 1215) \\
\hline 3 & "The practice of showing a particular quality in the form of a person, or an instance of this" & [44] (p. 1474) \\
\hline 4 & "The representation of a thing or a quality as a person" & [45] (p. 1704) \\
\hline 5 & "To think of or represent (ideas or objects) as having human qualities or human form" & [46] (p. 830) \\
\hline 6 & "Represent (an abstraction or thing) as having human characteristics" & [47] (p. 1031) \\
\hline 7 & "To think of or represent a quality or thing as a person (personify)" & [48] (p. 1704) \\
\hline 8 & "Type of metaphor in which human qualities are attributed to object, plant, animal, nature, etc." & [49] (p. 839) \\
\hline 9 & $\begin{array}{l}\text { "Personification means representing something that is without life as a human being or as having } \\
\text { human qualities" }\end{array}$ & [50] (p. 917) \\
\hline 10 & $\begin{array}{l}\text { "(1) Act of personifying, or that which personifies" } \\
\text { "(2) Attribution of personal form, character, etc." } \\
\text { "(3) A figure of speech in which an inanimate object or abstract idea is endowed with } \\
\text { personal attributes'" }\end{array}$ & [51] (p. 1077) \\
\hline 11 & "(An act of) Personifying a thing, quality, or idea" & [52] (p. 1420) \\
\hline 12 & "Literally to make or represent a character, to represent as a human being (personify)" & [53] (p. 585) \\
\hline 13 & $\begin{array}{l}\text { "(1) The attribution of a human nature or character to inanimate objects or abstract notions, esp. the } \\
\text { form of a person, as in art" } \\
\text { "(2) The representation of a thing or abstraction in the form of a person" }\end{array}$ & [54] (p. 1446) \\
\hline 14 & "To think of or represent as a person (personify)" & [55] (p. 389) \\
\hline 15 & "To regard animals or things as having human features (personify)" & [56] (p. 663) \\
\hline 16 & $\begin{array}{l}\text { "A figure of speech in which inanimate objects or qualities are spoken of as having } \\
\text { human characteristics" }\end{array}$ & [57] (p. 545) \\
\hline 17 & "The figurative endowment of inanimate objects or qualities with personality or human attributes" & [58] (p. 490) \\
\hline 18 & $\begin{array}{l}\text { "(1) The act of personifying or something that personifies" } \\
\text { "(2) To think of or represent (an inanimate object or abstraction) as having personality or the } \\
\text { qualities, thoughts, or movements of a living being (personify)" }\end{array}$ & [59] (p. 979) \\
\hline
\end{tabular}

Two significant dimensions of personification can be synthesised from the 18 definitions in Table 1 one includes human beings as creatures with spirits and the other includes everything but people while still using human characteristics to describe the non-human things. In other words, personification uses descriptions that apply to people on anything but human beings.

Chen [1], the editor of the collection of Yu's free verse, carefully selected the poems that would be included in the work, which consists of three volumes and 60 representative humorous verses. To help readers comprehend at a glance how the volumes are organised, a summary of the collection is given in Table 2.

Table 2. Organisation of the Collection of Humorous Free Verses by Kwang-Chung Yu.

\begin{tabular}{|c|c|c|c|c|c|c|}
\hline No. & Volume & No. of Verses & Properties & Features & Volume Length & No. of Lines \\
\hline 1 & Vol. 1 & 24 & $\begin{array}{l}\text { Lyric, narrative, } \\
\text { scenery, self-amusing, } \\
\text { and ridiculing }\end{array}$ & $\begin{array}{l}\text { Amusing and } \\
\text { interesting }\end{array}$ & Relatively short & $7-20$ \\
\hline 2 & Vol. 2 & 18 & Same as above & Same as above & Relatively long & $21-52$ \\
\hline 3 & Vol. 3 & 18 & $\begin{array}{l}\text { Social phenomena, } \\
\text { circumstances in the } \\
\text { world, and } \\
\text { environmental issues }\end{array}$ & $\begin{array}{l}\text { Bantering, sarcastic, } \\
\text { lamentable, and } \\
\text { disquieting }\end{array}$ & $\begin{array}{l}\text { Some short and some } \\
\text { long }\end{array}$ & $7-50$ \\
\hline
\end{tabular}

After a preliminary review of the work's features, the researcher analysed Yu's personification technique and how he applied it to various verses. Prior to diving into the collection, the researcher created a list of common definitions of personification found in scholarly works on linguistic analysis. These definitions were considered the norms for analysis and are featured in Table 3. 
Table 3. Scholarly definitions of personification.

\begin{tabular}{cll}
\hline No. & \multicolumn{1}{c}{ Definition } & Source \\
\hline 1 & "Comparing an object to a person and humanizing it" & {$[60]$ (p. 269) } \\
2 & "Describing an object or thing as a person" & {$[61]$ (p. 29) } \\
3 & "Describing an object expressing an emotion or doing something that only & {$[62]$ (p. 284) } \\
4 & "Dumans can express or do" & {$[63]$ (p. 120) } \\
5 & "Describing a thing as a person with emotions and thoughts" & {$[64]$ (p. 276) } \\
6 & "Giving things a human appearance, a human life, personality, and/or emotions" & {$[65]$ (p. 138) } \\
\hline
\end{tabular}

The researcher took all the definitions in Table 3 and summarised them as follows: the idea of personification is to describe an object or a thing lacking emotions, thoughts, and consciousness in such a way that it has at least one of the three. A deeper analysis of Yu's verses shows that all his uses of personification are related to one or more themes and revolve around the main subjects being described, that is, the objects or things lacking the emotions, thoughts, and consciousness mentioned above. In other words, the personified subjects are treated as if they were human. However, before discussing how personification was used, it is necessary to first discuss the personified themes.

For this study, three hypotheses were made.

Hypothesis 1. Personification occurs in over 50\% of the verses found in Collection of Humorous Free Verses by Kwang-Chung Yu.

Hypothesis 2. Only one theme is being personified in each of the verses with personification in the collection.

Hypothesis 3. The personified themes in the collection can be categorised into several different groups.

To test the hypotheses, six questions were designed for the study, and they are listed as follows:

1. How many of the collection's verses use personification?

2. How many of the verses in volume 1 contain personified themes?

3. How many of the verses in volume 2 contain personified themes?

4. How many of the verses in volume 3 contain personified themes?

5. How many of the verses in the collection as a whole contain personified themes?

6. How many different categories of personified themes exist across the entirety of the collection?

The study's findings will yield six results, which will be used to verify the research hypotheses. The result of question 1 will be used to verify Hypothesis 1 . The results of questions 2, 3, 4, and 5 will be used to verify Hypothesis 2 . And finally, the results of question 6 will be used to verify Hypothesis 3 .

\section{Methods}

The qualitative research method adopted in this study is the content analysis method. Wang [66] suggested that the content analysis method can be applied to the field of language and literature with the purpose of identifying an author's writing style and concepts. The literary content of a work is analysed by using sentences as the units. By considering any concepts that appear, the essence of the content being presented can be clarified and the meanings of the concepts can be confirmed to further illuminate the research themes. Then, after coding, the number of themes to be studied in the content can be obtained as a quantitative description. From there, the themes can be categorised into different groups [66]. Huang and Chien [67] have further stated that in cases of content analysis with sentences, more than one concept can exist. Thus, categorisation by field types is likely more appropriate.

Moreover, Yang, Wen, $\mathrm{Wu}$, and Lee argued that the main purpose of the content analysis method is to explore the influences the content has had on its readers [68]. In other words, the focus of a content analysis should be on analysing the effects of written communication. Thus, a content analysis may also feature some characteristics of a linguistic analysis. Overall, content analysis is 
centred on exploring any meanings hidden in the content of the literature through an appropriate unit of analysis (e.g., a word, term, theme, or meaning). After analysis, the number of times the unit appeared is obtained through coding and counting, a process that is adopted to meet the requirement of rigorous data collection $[69,70]$. In sum, many scholars agree that the essential elements of the content analysis method are the processes of concept analysis, coding, frequency counting, categorisation, and interpretation or inference. This approach is the study's theoretical foundation as well as the basis used to ensure that the research method is feasible.

The study uses the content analysis method, including coding, counting, and classification [66], to explore the content of the 60 free verse poems from the three volumes of Collection of Humorous Free Verses by Kwang-Chung Yu compiled by Chen [1]. Sentences are the unit of measurement. The purpose of this identification is to integrate concept analysis into the reading process and determine whether personification is used in an individual sentence. The researcher circled any sentences featuring personification and omitted those without it. The same identification method was applied throughout the three volumes to cover the 24 verses of volume 1 , the 18 verses of volume 2 , and the 18 verses of volume 3 ( 60 in total). The number of verses using personification was then tabulated. These results answer question 1: How many of the collection's verses use personification?

For each of the verses with circles, the number of personified themes was identified. But before doing this, it was necessary to clarify what a personified theme was. Put simply, a personified theme is a non-human theme that is described using human-related language. The number of things that count as being non-human is very broad since all objects (as opposed to subjects) are non-human. Such objects can include the living and non-living, abstract concepts, and anything without human consciousness; that is, the process identifies all descriptions of objects as human and specifies the number of objects that are described in this way. So the number of objects being personified is also referred to as the number of personified themes.

An example of this comes from the line, 'the wind is sighing and the cloud is crying' [1] (p. 227), where two personified themes are evident: the wind and the cloud. Although the two objects being described are not human, they are said to be sighing and crying as if they were. To present the number of personified themes in a more manageable way, four categories were created: verses with one theme, verses with two themes, verses with three themes, and verses with four or more themes. The number of verses from each of the volumes in these categories was tabulated and then the corresponding percentages calculated. The results answer questions 2, 3, and 4: How many of the verses in volume 1 contain personified themes? How many of the verses in volume 2 contain personified themes? How many verses in volume 3 contain personified themes?

After confirming the number of verses with personified themes in each of the volumes, the next step was to calculate the percentage of verses with one, two, three, or four or more personified themes. These results answer question 5: How many of the verses in the collection as a whole contain personified themes?

The personified themes were then coded with the aim of dividing all the themes into categories for further analysis. Then the categories were named and the number of verses and percentages in each category calculated. The results answer question 6: How many different categories of personified themes exist across the entirety of the collection? To help readers understand the personified themes summarised by this study, the categorised themes are listed after question 6 is answered in the results section. The names of the personified themes for each category are presented with corresponding frequencies and place of origin. The purpose of this display is to provide readers with insights into Yu's creative style based on the research results.

Systemisation and objectivity are stressed with regard to the study's method and process. Consistent standards have been established for identifying and analysing any content related to personification in the collection, which reflects the process known as systemisation. In the research process, objectivity lies in creating criteria for data selection and then performing selections based on sentences as units for the concept analysis. The principles guiding data selection and analysis 
were explained in the introduction and earlier in this methods section. The two key elements of these principles are as follows: (1) the use of non-human themes and (2) the description of a non-human theme as if it were a person. In other words, the basis of the study's content analysis is the aforementioned two-part standard used to systematically and objectively identify and record personified themes in Yu's free verse.

To further ensure objectivity in data selection and analysis, all circled content was checked eight times using the established standard featuring the two elements of personification. A table was created considering these two key elements and filled in with the selected content as the researcher reviewed the poems. Then every week, the content recorded in the table was checked to ensure it belonged in the data set. Each piece of content was considered from multiple perspectives. Whether the content was ultimately kept or discarded depended on the researcher's objective analysis and additional examination by peers. This way, the level of objectivity and precision required by the content analysis method was ensured.

To expand the scope of application for the research results, the study explores personification and related issues from a variety of perspectives in the discussion section.

\section{Results}

Based on the research questions and methodology, six different categories of personification were found: personification of the body (6 themes), personification of a plant (16 themes), personification of an animal (18 themes), personification of nature (33 themes), personification of a man-made object (19 themes), and personification of an abstract concept (10 themes). To ensure these findings are presented clearly, tables have been created to clearly display the results for questions 1-5 (Tables 4-8). Question 6 also has corresponding tables that answer the question in two layers. Under the first layer (Table 9), six categories (Tables 10-15) are used to display the 102 personified themes according to the identified types and their related content.

Table 4. Number of verses using personification among the 60 verses in the three volumes of Collection of Humorous Free Verses by Kwang-Chung Yu.

\begin{tabular}{ccccc}
\hline & Vol. 1 & Vol. 2 & Vol. 3 & Total \\
\hline Number of free verses & 24 & 18 & 18 & 60 \\
Number of free verses using personification & 24 & 18 & 11 & 53 \\
Percentage & $100 \%$ & $100 \%$ & $61.11 \%$ & $88.33 \%$ \\
\hline
\end{tabular}

Table 5. Number of personified themes from the 24 verses in volume 1 of Collection of Humorous Free Verses by Kwang-Chung Yu.

\begin{tabular}{ccccc}
\hline & $\mathbf{1}$ Theme & 2 Themes & 3 Themes & 4 or More Themes \\
\hline Number of verses & 12 & 7 & 4 & 1 \\
Percentage & $50 \%$ & $29.17 \%$ & $16.67 \%$ & $4.17 \%$ \\
Ranking & 1 & 2 & 3 & 4 \\
\hline
\end{tabular}

Table 6. Number of personified themes from the 18 verses in volume 2 of Collection of Humorous Free Verses by Kwang-Chung Yu.

\begin{tabular}{ccccc}
\hline & 1 Theme & 2 Themes & 3 Themes & 4 or More Themes \\
\hline Number of verses & 9 & 6 & 1 & 2 \\
Percentage & $50 \%$ & $33.3 \%$ & $5.56 \%$ & $11.11 \%$ \\
Ranking & 1 & 2 & 4 & 3 \\
\hline
\end{tabular}


Table 7. Number of personified themes from the 11 verses in volume 3 of Collection of Humorous Free Verses by Kwang-Chung Yu.

\begin{tabular}{ccccc}
\hline & $\mathbf{1}$ Theme & 2 Themes & 3 Themes & 4 or More Themes \\
\hline Number of verses & 4 & 5 & 1 & 1 \\
Percentage & $36.36 \%$ & $45.45 \%$ & $9.09 \%$ & $9.09 \%$ \\
Ranking & 2 & 1 & 3 & 3 \\
\hline
\end{tabular}

Table 8. Number of personified themes in the 53 verses featuring personification in Collection of Humorous Free Verses by Kwang-Chung Yu.

\begin{tabular}{ccccc}
\hline & 1 Theme & 2 Themes & 3 Themes & 4 or More Themes \\
\hline Number of verses & 25 & 18 & 6 & 4 \\
Percentage & $47.17 \%$ & $33.96 \%$ & $11.32 \%$ & $7.55 \%$ \\
Ranking & 1 & 2 & 3 & 4 \\
\hline
\end{tabular}

Table 9. Six categories for the 102 personified themes in Collection of Humorous Free Verses by Kwang-Chung Yu.

\begin{tabular}{ccccccc}
\hline No. & Category & Vol. 1 & Vol. 2 & Vol. 3 & Total & Percentage \\
\hline 1 & personification of the body & 2 & 3 & 1 & 6 & $5.88 \%$ \\
2 & personification of a plant & 9 & 6 & 1 & 16 & $15.69 \%$ \\
3 & personification of an animal & 6 & 7 & 5 & 18 & $17.65 \%$ \\
4 & personification of nature & 17 & 12 & 4 & 33 & $32.35 \%$ \\
5 & personification of a man-made object & 3 & 5 & 11 & 19 & $18.63 \%$ \\
6 & personification of an abstract concept & 6 & 3 & 1 & 10 & $9.8 \%$ \\
\hline
\end{tabular}

Table 10. Six themes falling under type 1 personification.

\begin{tabular}{cccccc}
\hline No. & Theme & Frequency & No. & Theme & Frequency \\
\hline 1 & heart & 1 & 4 & tooth & 1 \\
2 & bladder & 1 & 5 & tongue & 1 \\
3 & pustule & 1 & 6 & cirrhosis & 1 \\
\hline
\end{tabular}

Table 11. Sixteen themes for type 2 personification.

\begin{tabular}{cccccc}
\hline No. & Theme & Frequency & No. & Theme & Frequency \\
\hline 1 & tree & 7 & 5 & sugar cane & 1 \\
2 & leaf & 4 & 6 & moss & 1 \\
3 & daffodil & 1 & 7 & pine cones & 1 \\
4 & mango & 1 & 8 & - & - \\
\hline
\end{tabular}

Table 12. Eighteen themes for type 3 personification.

\begin{tabular}{cccccc}
\hline No. & Theme & Frequency & No. & Theme & Frequency \\
\hline 1 & cricket & 3 & 8 & gecko & 1 \\
2 & snail & 2 & 9 & dog & 1 \\
3 & frog & 2 & 10 & swallow & 1 \\
4 & pigeon & 1 & 11 & butterfly & 1 \\
5 & duck & 1 & 12 & sparrow & 1 \\
6 & bird & 1 & 13 & cat & 1 \\
7 & cockroach & 1 & 14 & ant & 1 \\
\hline
\end{tabular}


Table 13. Thirty-three themes for type 4 personification.

\begin{tabular}{ccccccccc}
\hline No. & Theme & Frequency & No. & Theme & Frequency & No. & Theme & Frequency \\
\hline 1 & wind & 5 & 7 & sun & 2 & 13 & rain & 1 \\
2 & stone & 4 & 8 & night & 2 & 14 & river & 1 \\
3 & snow & 3 & 9 & moon & 2 & 15 & ice & 1 \\
4 & cloud & 3 & 10 & dusk & 1 & 16 & mountain & 1 \\
5 & fog & 2 & 11 & starlight & 1 & 17 & earth & 1 \\
6 & sea & 2 & 12 & galaxy & 1 & - & - & - \\
\hline
\end{tabular}

Table 14. Nineteen themes for type 5 personification.

\begin{tabular}{cccccccccccc}
\hline No. & Theme & Freq. $^{\mathbf{1}}$ & No. & Theme & Freq. & No. & Theme & Freq. & No. & Theme & Freq. \\
\hline 1 & highway & 2 & 6 & bridge & 1 & 11 & speaker & 1 & 16 & chair legs & 1 \\
2 & abandoned cannon & 1 & 7 & tung oil lamps & 1 & 12 & excavator & 1 & 17 & anchor & 1 \\
3 & lighthouse & 1 & 8 & machine gun & 1 & 13 & house & 1 & 18 & kite & 1 \\
4 & street lights & 1 & 9 & TV set & 1 & 14 & bill & 1 & - & - & - \\
5 & city & 1 & 10 & firecracker & 1 & 15 & chimney & 1 & - & - \\
\hline \multicolumn{10}{c}{ 1 Freq. } & Frequency.
\end{tabular}

Table 15. Ten themes for type 6 personification.

\begin{tabular}{ccccccccc}
\hline No. & Theme & Freq. $^{\mathbf{1}}$ & No. & Theme & Freq. & No. & Theme & Freq. \\
\hline 1 & horizontal line & 2 & 5 & Heaven & 1 & 9 & spirit of the sea & 1 \\
2 & space & 1 & 6 & tip & 1 & 10 & - history \\
3 & years & 1 & 7 & fortune & 1 & - & - \\
4 & myth & 1 & 8 & fantasy land & 1 & - & - \\
\hline
\end{tabular}

\subsection{The Number of Verses Using Personification}

All 42 verses in volumes 1 and 2 contain some narration using personification, while 11 of the 18 verses in volume 3 contain some narration using personification, as shown in Table 4.

The verses in volumes 1 and 2 include extended lyric, narrative, and scenic verses as well as verses using ridicule. Personification is found in each kind of verse. In comparison, the verses in volume 3 are chiefly sarcastic and consist of short lines. The use of personification is not as common in volume 3.

\subsection{The Number of Verses with Personified Themes in Volume 1}

Half of the 24 verses in volume 1 contain one personified theme, which is three times as many as the number of verses containing three personified themes and 1.7 times as many as those containing two personified themes. The number of verses containing four or more personified themes is one, which is the lowest value. Table 5 summarises these findings.

Most of the verses in volume 1 with less than 20 lines contain one personified theme, followed by verses with two, three, and four or more personified themes in descending order.

\subsection{The Numbers of Verses with Personified Themes in Volume 2}

Half of the 18 verses in volume 2 contain one personified theme, which is 1.5 times as many as the number of verses containing two personified themes and 4.5 times as many as those containing four or more personified themes. The number of verses containing three personified themes is one, which is the lowest value. Table 6 summarises these findings.

Most of the verses in volume 2 with fewer than 20 lines contain one personified theme, followed by verses with two, three, and four or more personified themes in descending order. 


\subsection{The Number of Verses with Personified Themes in Volume 3}

Of the 11 verses in volume 3, five contain two personified themes, which is 1.25 times as many as the number of verses containing one theme and five times as many as those containing three personified themes and four or more personified themes. Table 7 summarises these findings.

The verses in volume 3 consider social phenomena and have various numbers of lines, five of which contain two personified themes, followed by those with one personified theme (four verses) and then three (one verse) or four or more personified themes (one verse).

\subsection{The Number of Verses with Personified Themes}

Of the 53 verses that feature personification in the three volumes, 25 contain one personified theme, which is 1.3 times as many as the number of verses containing two personified themes, 4.1 times as many as those containing three personified themes, and 6.2 times as many as those containing four or more personified themes. Table 8 summarises these findings.

Of all the verses featuring personification across the three volumes, the shortest verse had seven lines and the longest verse had 52. Most of the verses contain one personified theme, followed by those with two, three, and four or more personified themes in descending order.

\subsection{The Six Categories for the 102 Personified Themes}

Across all three volumes of the collection, there are 102 personified themes, which, after analysis, were categorised into six groups: personification of the body ( 6 themes), personification of a plant (16 themes), personification of an animal (18 themes), personification of nature (33 themes), personification of a man-made object (19 themes), and personification of an abstract concept (10 themes). These findings are summarised in Table 9.

Across the three volumes, personification of nature had the largest number of personified themes, followed in descending order by the categories of personification of a man-made object, personification of an animal, personification of a plant, personification of an abstract concept, and personification of the body.

\subsubsection{Type 1: Personification of the Body}

In the collection as a whole, six themes fall in the category of the body being personified (see Table 10).

Of the six personified themes relating to the body, three are organs and one each are either a structure for digestion, a symptom, or a disease.

\subsubsection{Type 2: Personification of a Plant}

Considering the entire collection, there are 16 themes that fit into the category of a plant being personified (see Table 11).

Of the 16 personified themes for a plant, seven are repeats for a tree and four are repeats for a leaf. The rest of the themes are only mentioned once.

\subsubsection{Type 3: Personification of an Animal}

Across the collection, there are 18 themes in this category for personified animals (see Table 12).

Of the 18 themes for the personification of an animal, three are repeats for a cricket and two each are repeats for a snail and a frog. The rest of the themes are only mentioned once.

\subsubsection{Type 4: Personification of Nature}

Looking at the entire collection, there are 33 themes in the category of personifying nature (see Table 13). 
Of the 33 personified themes dealing with nature, five are repeats for the wind; four are repeats for a stone; three each are repeats for snow and a cloud; and two each are repeats for the fog, sea, sun, night, and moon. The rest of the themes are only mentioned once.

\subsubsection{Type 5: Personification of a Man-Made Object}

In the collection as a whole, there are 19 themes in the category of personifying a man-made object (see Table 14).

Of the 19 personified themes relating to a man-made object, two are repeats for a highway while the remaining themes are only mentioned once.

\subsubsection{Type 6: Personification of an Abstract Concept}

Across the entirety of the collection, there are 10 themes that fall in this category of personifying an abstract concept (see Table 15).

Of the 10 personified themes dealing with an abstract concept, two are repeats for a horizontal line while the remaining themes are only mentioned once.

\section{Discussion}

The above findings illustrate how Yu used personification in his free verse. Emotion is the source of his creative energy, and this section reveals that Yu's writing techniques are not isolated but rather mutually reinforcing. The reason behind this viewpoint is that in content analysis concepts are usually mutually exclusive while also being mutually tolerant [66]. Thus, the following discussion shows how the results described in the methods section regarding the categorisation of the selected themes do not ultimately detail mutually exclusive concepts. The categories of personified themes and the reflection shortcuts and ideal situations for personification listed in this section have been determined based on a reader's likely application needs.

To help readers understand Yu's descriptive personification, the verses are further analysed and discussed according to two elements $(A$ and $B$ ) for content selection. Element $A$ is the personified theme, which is italicised for emphasis within the quoted material. Element $B$ is the description of the theme and is the rest of the quoted material. The discussion contains three parts: (1) an analysis of the six categories of personification for language education, (2) eight major reflection shortcuts for personification within language education, and (3) the association and application of eight types of situations for personification within language education.

\subsection{Analysis of the Six Categories of Personification for Language Education}

\subsubsection{Type 1: Personification of the Body}

Verses within this personification type consider the body or related elements as a person with an independent will. The concepts used in these verses include (1) a comparison of the sudden discovery of a pustule to being attacked by a villain, "a pustule invaded and attacked in the dark" [1] (p. 124), and (2) a comparison of cirrhosis to a murderer, "cirrhosis killed the famous martial arts novel writer" [1] (p. 212).

\subsubsection{Type 2: Personification of a Plant}

Verses within this personification type consider a living plant as a person with human characteristics. The concepts used in these verses include (1) a description of a narcissus as having a noble facial expression without any smile, "the narcissus wouldn't even show a smile with his aristocratic eyes" [1] (p. 168); (2) a description of static moss as having a stupid look while not answering a question, "let me ask you, stupid moss" [1] (p. 137); and (3) a comparison of a begonia to a person who can make decisions, "asking if the begonia agreed" [1] (p. 133). 


\subsubsection{Type 3: Personification of an Animal}

Verses within this personification type consider an animal as a person. The concepts used in these verses include (1) a comparison of a house lizard's skill of hanging upside down to a unique martial arts skill featured in a martial arts novel, "did you teach the grey loner [the house lizard] the levitation kung fu?" [1] (p. 144), and (2) a description of a cat as a crafty person, "to a sophisticated blind cat" [1] (p. 21).

\subsubsection{Type 4: Personification of Nature}

Verses within this personification type consider a natural object to be a person. The concepts used in these verses include (1) a description of the blue ocean in the third person with expressions regarding his eyes, "his [the blue ocean's] blue eyes" [1] (p. 153), and (2) the consideration of starlight as a person, "giving the starlight a chance" [1] (p. 96).

\subsubsection{Type 5: Personification of a Man-Made Object}

Verses within this personification type consider a man-made object as a person. The concepts used in these verses include (1) a comparison of the weird sound coming from the legs of a chair being moved to the moaning sound of humans based on the author's subjective feelings towards hearing, "the four chair legs already started to moan" [1] (p. 252), and (2) a comparison of the phenomenon of dark smoke rising from a chimney to a lawless and godless person, "being absolutely unrestrained and flicking away smoke bits arrogantly" [1] (pp. 226-227).

\subsubsection{Type 6: Personification of an Abstract Concept}

Verses within this personification type consider a non-concrete and non-physical thing that can be understood conceptually only if seen as a person. The concepts used in these verses include (1) the consideration of a thing without any physical existence as a second person, "someone asked you to be a horizontal line. If I can find your zipper, I can unzip the mask of the space" [1] (p. 71), and (2) a comparison of the abstract concept of time to a person, "I wouldn't be caught by the passing of time" [1] (p. 93).

\subsection{Eight Major Reflection Shortcuts for Personification within Language Education}

\subsubsection{Using a Human Facial Expression}

This shortcut calls on the writer to describe a thing using a human facial expression. Examples from Yu include (1) a description of a static object as having a concentrated gaze, "the abandoned cannon looked into the distance" [1] (p. 24), and (2) a description of an insect as having a disappointed look, "the butterfly being blackened by smoke gazed desperately" [1] (p. 227).

\subsubsection{Using Human Imagination}

This shortcut centres on describing a thing as having an imagination. Examples from Yu include (1) a comparison of a dreamland to an arrogant and overbearing person, "the dreamland was forceful" [1] (p. 175), and (2) a comparison of the breeze to a runner, "who can stop the breeze" [1] (p. 169).

\subsubsection{Using a Human Movement}

This shortcut relies on describing a dynamic object or scene with a human movement. Examples from $\mathrm{Yu}$ include (1) a comparison of being hit by flying snowflakes to being beaten, "being slapped by the snow" [1] (p. 28), and (2) a comparison of a scene with the bottom half of the setting sun being blocked by dynamic dark clouds to the shape of a person's mouth when talking, "the setting sun said that the fragments of the rosy clouds were his signature" [1] (p. 46). 


\subsubsection{Using Human Emotion}

This shortcut is about projecting a subjective emotion onto an object using empathy. Examples from $\mathrm{Yu}$ include (1) the projection of anger onto a cloud, "an angry cloud surrounded and trapped me" [1] (p. 32), and (2) a description of an animal's plaintive cry using the feeling of sorrow Yu experiences from hearing it, "the cricket sang sorrowfully" [1] (p. 36).

\subsubsection{Using a Human Ability}

This shortcut centres on describing an object using a human ability. Examples from Yu include (1) a description of a plant as having the ability to tell stories, "which old tree could tell his own story so frankly" [1] (p. 74), and (2) a description of an animal as lacking expressive ability, "there was no bird that could illustrate this clearly" [1] (p. 117).

\subsubsection{Using a Human Attitude}

This shortcut focuses on psychological depictions. Examples from Yu include (1) a description of a pine cone perhaps falling on the poet's head with human intentionality, 'the pine cone might not be intentional' [1] (p. 52), and (2) a description of an animal as having a human psychological state, 'all the house lizards were not vigilant under the bright light' [1] (p. 146).

\subsubsection{Using a Human Image}

This shortcut is about describing the appearance or shape of an object with a human image. Examples from Yu include (1) an imaginative comparison of a snail with its shell to a soldier wearing a helmet, "this stubborn trooper" [1] (p. 132), and (2) a comparison of a scene with tall blue-green sugar cane to an honour guard carrying rifles in a military parade, "reviewing the cyan honour guards" [1] (p. 110).

\subsubsection{Using a Human Characteristic}

This shortcut relies on describing an object or an abstract concept using an innate human characteristic or a characteristic shown in daily life. Examples from Yu include (1) a description of an inanimate object as having human stubbornness, "teaching this stubborn stone" [1] (p. 87), and (2) a comparison of a piece of paper to someone's clear train of thought, "the bill is clear-headed" [1] (p. 246).

\subsection{The Association and Application of Eight Types of Situations for Personification within Language Education}

The following are descriptions of specific types of social or cultural situations where using personification to make associations can help enhance an audience's understanding of what the writer intends to express.

\subsubsection{A Critical Situation}

A critical situation can be described using personification. For example, Yu associated the moment of sticking a pole in the ground for pole-vaulting with the critical situation of hand-to-hand combat: "choosing the vital part of the body and stab in it bravely, before the enemy can scream" [1] (p. 164).

\subsubsection{Comparison and Insinuation}

Directly or indirectly, the differences between the descriptions of two (or more) personified themes can be presented using comparisons, and these comparisons usually have a hidden insinuation or sarcastic meaning. For example, Yu compared two different scenes from nature to two different sets of attitudes and skills. Readers can easily understand "that moon was a beautiful but fickle witch/translation was her specialty/however, the world was not translated as desired" [1] (p. 178) 
while "the snow was another translator of aesthetics/she intentionally translated the world wrong" [1] (p. 179).

\subsubsection{The Dynamic and Static}

A situation ripe for personification is one where various dynamic and static images are being associated with observations. For example, through observation, Yu compares the strange shape of a rock on the seashore that has been struck by waves to a frog. Here $\mathrm{Yu}$ is juxtaposing the dynamic waves to a person who is talking to the static frog-shaped rock: "the sea has been calling you under your feet for thousands of years/how come you [the frog-shaped rock] are still squatting down by the shore?" [1] (p. 78).

\subsubsection{Conflict}

When a disharmonious phenomenon in one's surroundings has been discovered, personification can be used to compare it to a conflict in life. For example, Yu compared two unrelated sounds to an argument between two people when he wrote "firecrackers and horns, please stop fighting" [1] (p. 219).

\subsubsection{Contrast}

Personification works well in situations focused on identifying two contrasting themes to form a description with a contrasting structure. For example, Yu describes two different sounds in terms of their frequency, speed, volume, pitch, range, and echoes to create clear strong-weak associations with a debate going on between two people: "who do you think will win the debate between the cricket and the machine gun?/Of course the machine gun will win/he is eloquent with strong and fast words coming out through his sharp tongue" [1] (p. 206).

\subsubsection{Role and Plot}

In this situation, first, the object is described using a suitable human character and then a plot is designed based on the character, or the same issue is described using two different personified themes. For example, Yu called the ice his paternal aunt and the snow his maternal aunt. By comparing them to family members, he shows his concern for the ecosystem. Yu also describes the disappearing ice and snow with words such as crying and fleeing to show his disquiet about global warming in a humorous way: "Aunt Ice, please stop crying/if you keep on crying, there will be no home for polar bears... Aunt Snow, please stop fleeing, if you keep on fleeing, you may actually get lost" [1] (pp. 258-259).

\subsubsection{Quality of Life}

Personification is useful when the writer is seeking to discover or is concerned about how the quality of life is being damaged. Related issues include those where the quality of life is being threatened by something in the natural or cultural environment. For example, Yu used personification with symbolisation to vividly describe pollution by conjuring up the image of dark chimneys of smoke "showing that rude and unreasonable attitude... spitting out the filthy language which your mind is filled with" [1] (p. 226-227).

\subsubsection{Change in Time and Space}

This situation is centred on identifying the passage of time to describe changes in a scene. For example, Yu compared the phenomenon of the sky at dusk turning dark gradually to two characters showing up one after another. This description is told from the perspective of time. As time goes by, the rosy clouds in the sky at dusk, like gems, disappear as the night falls. The description then changes to the perspective of space, and Yu compared the disappearing dusk to the process of being smuggled in a rather vivid way: "in the end, how did the dusk, the stowaway/cross the border? / And how did 
the night from the black gang/come to his aid?/How come after a short moment of distraction/all the amethyst, red agates, and topazes across the sky/were smuggled altogether?" [1] (p. 62).

\subsection{Survey of the Applicability of the Analytical Results Presented in the Research Discussion}

\subsubsection{Online Questionnaire}

To determine the applicability of this study, an online questionnaire was used to determine the effectiveness of the analysis using the examples presented in the discussion section. The respondents were 134 students from three cohorts that had taken a relevant Chinese course. Group A had 37 students, group B had 36 students, and group $C$ had 61 students, resulting in a total of 134 students; however, only 126 students completed the online questionnaire: 35 from group A, 35 from group B, and 56 from group $C$. The survey results indicate that most students gave positive feedback and used the eight recommended shortcuts.

The survey consisted of multiple-choice questions. Most of the questions included options drawn from a 5-point Likert scale, and two questions asked respondents to choose the most effective personification technique. Before the online survey was distributed, the researcher spent four hours (two hours each week over two weeks) with the participants explaining the analytical results using the examples presented for the three main topics featured in the discussion section and taught the participants how to write their own free verse. The students were encouraged to read Yu's poems and write verses of their own outside of lesson time. After two weeks, the students filled in the questionnaire within a specified time using their smartphones. Considering all the students from groups A, B, and C, $94 \%$ of them completed the questionnaire. The findings of the questionnaire are analysed and summarised below.

\subsubsection{The Scale and Questions}

Using a 5-point Likert scale ( 5 = strongly agree, $1=$ strongly disagree), the following questions were asked: (Q1) Do you agree that the analysis of the personification examples in the research discussion section are helpful in understanding Yu's free verse? (Q2) Do you agree that the analysis of the personification examples in the research discussion section are helpful in writing new free verse? (Q3) Do you agree that the analysis of the examples of the six categories of personification in the research discussion section are helpful in conceiving ideas for writing new free verse? (Q4) Do you agree that the analysis of the examples of the eight major reflection shortcuts for personification in the research discussion section are helpful in knowing what techniques to use to write new free verse? (Q5) Do you agree that the analysis of the examples of the association and application of eight types of situations in the research discussion section are helpful in writing new free verse?

The responses to the questionnaire are summarised in Table 16.

Table 16. Results of the survey for the applicability of the analysis of the personification examples.

\begin{tabular}{|c|c|c|c|c|c|c|}
\hline \multirow{2}{*}{ Scale } & \multirow{2}{*}{ Group $^{1}$} & Q1 & Q2 & Q3 & Q4 & Q5 \\
\hline & & \multicolumn{5}{|c|}{$\%^{2}$} \\
\hline \multirow{3}{*}{ Strongly agree } & A & 51.43 & 42.86 & 48.57 & 62.86 & 45.71 \\
\hline & B & 45.71 & 48.57 & 40 & 42.86 & 48.57 \\
\hline & $\mathrm{C}$ & 55.36 & 51.79 & 53.57 & 58.93 & 50 \\
\hline \multirow{3}{*}{ Agree } & $\mathrm{A}$ & 45.71 & 51.43 & 40 & 37.14 & 51.43 \\
\hline & B & 45.71 & 37.14 & 45.71 & 42.86 & 37.14 \\
\hline & $\mathrm{C}$ & 35.71 & 41.07 & 39.29 & 37.50 & 41.07 \\
\hline \multirow{3}{*}{$\begin{array}{l}\text { Neither agree nor } \\
\text { disagree }\end{array}$} & A & 2.86 & 5.71 & 11.43 & 0 & 2.86 \\
\hline & $\mathrm{B}$ & 8.57 & 14.29 & 11.43 & 14.29 & 14.29 \\
\hline & C & 8.93 & 7.14 & 5.36 & 1.79 & 8.93 \\
\hline \multirow{3}{*}{ Disagree } & A & 0 & 0 & 0 & 0 & 0 \\
\hline & $\mathrm{B}$ & 0 & 0 & 0 & 0 & 0 \\
\hline & $\mathrm{C}$ & 0 & 0 & 1.79 & 1.79 & 0 \\
\hline \multirow{3}{*}{ Strongly disagree } & A & 0 & 0 & 0 & 0 & 0 \\
\hline & B & 0 & 0 & 2.86 & 0 & 0 \\
\hline & C & 0 & 0 & 0 & 0 & 0 \\
\hline
\end{tabular}

${ }^{1}$ Number of persons in group A, 35; group B, 35; and group C, $56 .{ }^{2}$ All numbers are expressed as percentages. 
Of the 35 students in group A, 95.43\% agreed or strongly agreed with all five questions. Of the 35 students in group B, 86.85\% agreed or strongly agreed with all five questions. Of the 56 students in group C, $92.86 \%$ agreed or strongly agreed with all five questions.

\subsubsection{The Most Effective Major Reflection Shortcuts for Personification}

The question was presented to the students as follows: Of the eight major reflection shortcuts for personification, which one was the most effective? For this question, each participant could select only one option. The results for this question about the eight major reflection shortcuts are shown in Table 17.

Table 17. Results of question regarding the most effective of the eight major reflection shortcuts for personification.

\begin{tabular}{cccccccccc}
\hline \multicolumn{2}{c}{ Shortcut $^{1}$} & $\# 1$ & $\# \mathbf{2}$ & \#3 & \#4 & \#5 & \#6 & \#7 & \#8 \\
\hline Group & No. of Persons & \multicolumn{7}{c}{$\mathbf{\%}^{\mathbf{2}}$} \\
\hline A & 35 & 5.71 & 42.86 & 0 & 40 & 2.86 & 2.86 & 2.86 & 2.86 \\
B & 35 & 2.86 & 60 & 0 & 17.14 & 0 & 11.43 & 5.71 & 2.86 \\
C & 56 & 3.57 & 42.86 & 5.36 & 26.79 & 1.79 & 8.93 & 1.79 & 8.93 \\
\hline
\end{tabular}

${ }^{1}$ For more on shortcuts 1-8, see Sections 4.2.1-4.2.8. ${ }^{2}$ All numbers are expressed as percentages.

The most effective major reflection shortcuts for personification according to the 35 students in group A and the 35 students in group B were shortcuts \#2, \#4, and \#6 in descending order of preference. Meanwhile, group C (56 students) chose shortcuts \#2, \#4, and \#6/\#8, also in descending order.

\subsubsection{The Most Effective of the Eight Types of Situations for Personification}

The question was asked as follows: Of the eight types of situations for personification that were presented for association and application, which was the most effective? For this question, each participant could select only one option. The results for this question about the eight types of situations for association and application are shown as percentages in Table 18.

Table 18. Results of the survey for the most effective of the eight types of situations for personification association and application.

\begin{tabular}{cccccccccc}
\hline \multicolumn{2}{c}{ Situation $^{1}$} & \#1 & \#2 & \#3 & \#4 & \#5 & \#6 & \#7 & \#8 \\
\hline Group & No. of Persons & \multicolumn{7}{c}{$\mathbf{\%}^{\mathbf{2}}$} \\
\hline A & 35 & 5.71 & 28.57 & 14.29 & 5.71 & 11.43 & 17.14 & 5.71 & 11.43 \\
B & 35 & 0 & 25.71 & 22.86 & 2.86 & 17.14 & 22.86 & 0 & 8.57 \\
C & 56 & 3.57 & 19.64 & 12.50 & 8.93 & 14.29 & 35.71 & 1.79 & 3.57 \\
\hline
\end{tabular}

${ }^{1}$ For more on situations 1-8, see Sections 4.3.1-4.3.8. ${ }^{2}$ All numbers are expressed as percentages.

The most effective of the eight types of situations selected by group A (35 students) were situations $\# 2$, \#6, and \#3, listed in descending order of preference. Those selected by group B (35 students) were $\# 2$, \#3, \#6, and \#5 in descending order, and those selected by group C (56 students) were \#6, \#2, and \#5, also in descending order of preference.

Of the 134 students who participated in the online questionnaire, 126 completed the survey. Of these respondents, $91.71 \%$ gave positive feedback (agree or strongly agree). For this reason, the researcher believes that the three main topics and their associated subtopics, concepts, and methods specified in the discussion section together with the 55 examples of Yu's free verse should be considered effective teaching tools. 


\section{Conclusions}

Three hypotheses were considered in this study using five research questions. The study's conclusions are summarised below. (1) According to the findings concerning research question 1, personification occurs in 53 of Yu's 60 verses (88.33\%) featured in the collection. Therefore, Hypothesis 1 , which states that "Personification occurs in over $50 \%$ of the verses found in Collection of Humorous Verses by Kwang-Chung Yu", stands. (2) According to the findings concerning questions 2, 3, and 4, the number of personified themes differs across the three volumes of the collection. However, the frequency of the number of themes appearing in one verse is sometimes the same. For example, in both volumes 1 and 2, most of the verses have one theme only, followed by two themes as the second most frequent occurrence. See Table 19 for details.

Table 19. The ranking and number of personified themes in Collection of Humorous Free Verses by Kwang-Chung Yu.

\begin{tabular}{ccccccccc}
\hline \multirow{2}{*}{ No. of Themes } & \multicolumn{2}{c}{ 1 Theme } & \multicolumn{2}{c}{ 2 Themes } & \multicolumn{2}{c}{ 3 Themes } & \multicolumn{2}{c}{ 4 or More Themes } \\
\cline { 2 - 9 } & Ranking & No. & Ranking & No. & Ranking & No. & Ranking & No. \\
\hline Vol. 1 & 1 & 12 & 2 & 7 & 3 & 4 & 4 & 1 \\
Vol. 2 & 1 & 9 & 2 & 6 & 4 & 1 & 3 & 2 \\
Vol. 3 & 2 & 4 & 1 & 5 & 3 & 1 & 3 & 1 \\
Total & 1 & 25 & 2 & 18 & 3 & 6 & 4 & 4 \\
\hline
\end{tabular}

Based on Table 19, the number of verses containing one to four or more themes differs for each volume in the collection. However, overall, most of the verses contain one personified theme $(41.17 \%)$, followed by two personified themes (33.96\%) as the second most frequent occurrence, three personified themes $(11.32 \%)$ as the third most frequent, and finally four or more personified themes $(7.55 \%)$ as the least frequent occurrence. Therefore, Hypothesis 2, which states that 'Only one theme is being personified in each of the verses with personification in the collection', does not stand. It is arguable, however, that quality rather than quantity is more important with personified themes.

According to the findings concerning questions 5 and 6, the personified themes can be categorised into six groups as follows in descending order: (1) personification of nature has the highest number of themes, 33 (32.35\%); (2) personification of a man-made object has 19 themes $(18.63 \%)$; (3) personification of an animal has 18 themes (17.65\%); (4) personification of a plant has 16 themes (15.69\%); (5) personification of an abstract concept has 10 themes $(9.8 \%)$; and (6) personification of the body has six themes $(5.88 \%)$, the lowest number. This confirms Hypothesis 3 , which states that "The personified themes in the collection can be categorised into several different groups". It may be inferred from this result that the best way to think of an idea for personification is to associate the subject with non-living scenes, objects, or sights because nature is boundless and therefore a limitless resource for inspiration and creation. Another useful approach is to consider man-made and physical objects for personification. From this study, then, the researcher concludes that the natural environment and cultural considerations are key resources for the use of personification in Yu's poetry.

This study explored Yu's personification technique and summarises five key concepts and their interactions to yield a pragmatic analysis of a personification model for language education, as shown in Figure 1.

In this model, the personification process begins with sensual media. The feelings of non-living things and phenomena are projected or applied to the behavioural or cultural situations of humans through subjective emotional shifts or objective scenario associations that add humour and humanity to the personification. Finally, this process results in a new model for the pragmatic analysis of personification skills in language education. The model is a high-level presentation of language aesthetics. It can show readers the specific concepts underlying one literary master's personification technique. In other words, the personification model is a study of a master poet and is sure to be of interest to anyone who wants to know how personification techniques are crafted. 


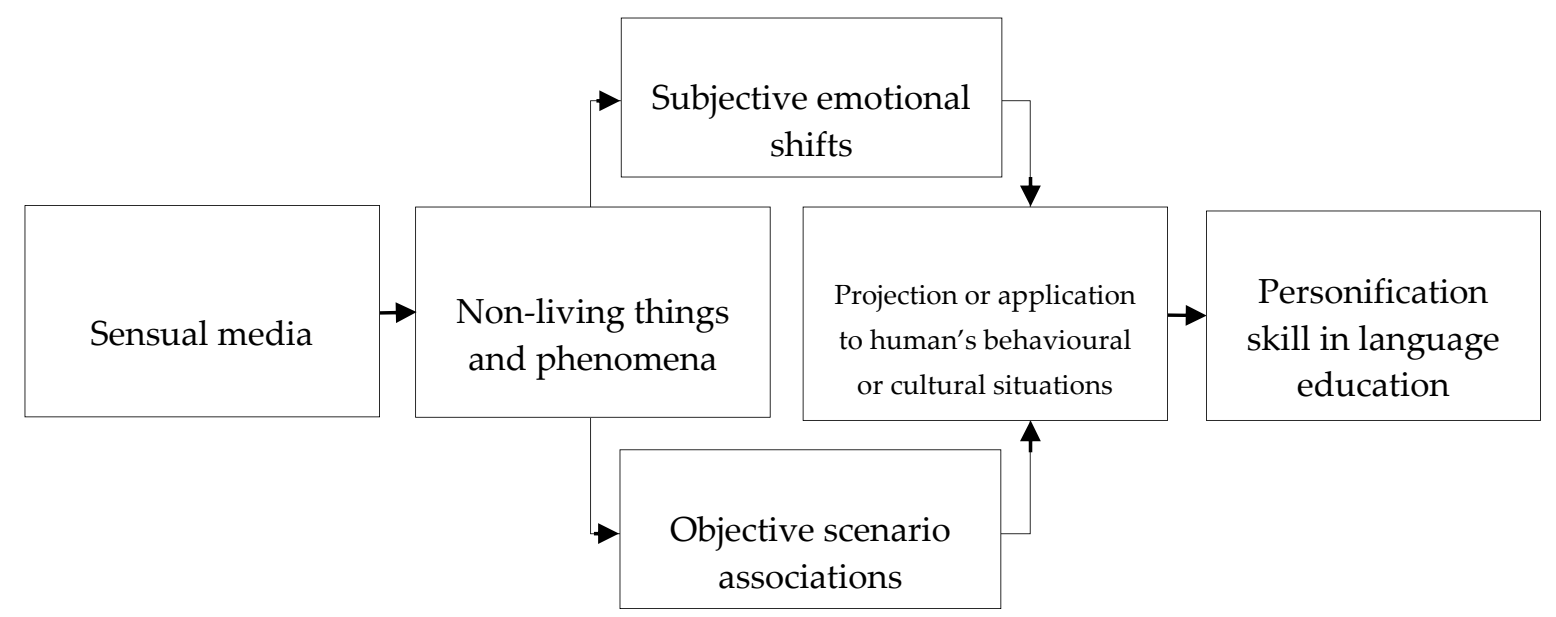

Figure 1. A pragmatic analysis of a personification model for language education.

In this model, the senses are the core medium for the expression of personification. Information received through the senses can be readily associated with specific situations in human societies and cultures and then subsequently described using comparisons. This application of the senses is the most crucial consideration for personification. Training students in language education to become adept at using personification relies on getting them to understand the themes best suited for making comparisons. In total, there are eight different strategies using a single sense or multiple senses that can be employed when teaching students how to effectively incorporate personification in their own writing. All eight strategies are summarised in the following paragraphs.

First, students should train their sense of sight. This strategy focuses on developing an individual's imaginative abilities using feelings that are inspired by sight in order to identify themes ripe for personification. Examples from $\mathrm{Yu}$ that can be used as a starting point for students include (1) the personification of a static object, "the old TV always stayed in the corner" [1] (p. 210); (2) the personification of a dynamic animal, "describing the scattering cockroaches with a smuggling ring" [1] (p. 121); and (3) the personification of a large object, "a whole row of houses eager for action/a whole impatient road" [1] (p. 232).

Second, students should train their sense of hearing. This strategy emphasises developing the imagination with regard to feelings based on hearing in order to choose appropriate themes for personification. Some examples from Yu that can serve as useful references for students include (1) the comparison of sounds heard in nature to sounds made by humans, "the nervous maple had a dry cough" [1] (p. 21); (2) the development of imagination based on tonal qualities, "the horizontal line/he speaks the dialect of the sailors/his labial sounds are soft and gentle/his guttural sounds are deep and strong" [1] (pp. 153-154); and (3) the development of imagination based on the volume of a sound, "the sound volume of his snoring shows his incredible vital capacity" [1] (p. 155).

Third, students should train their sense of touch. This strategy is aimed at honing the imagination so that students are better able to identify feelings based on physical interactions with the skin or an organ and translate them into themes for personification. Two illustrative examples from Yu include (1) the feeling that a loaded bladder is like an independent person with a consciousness, "the full bladder will just call you back from far away" [1] (p. 83), and (2) the comparison of getting rid of feelings of restraint to the ground while pole-vaulting "to [an] escape from the captivity of the God of the Earth" [1] (p. 165).

Fourth, students should train their sense of sight in conjunction with their sense of hearing. This strategy centres on developing the imagination for personification using feelings that come from sight and hearing. For example, Yu compares a scene with a pond that he sees before his eyes and his observations of the animals in the pond calling to one another to the scene of a human meeting filled 
with noisy discussion: "is the shallow pond a meeting room?/ there are so many elegant men in white dress/with them the room is abuzz" [1] (p. 90).

Fifth, students should train their senses of sight and touch together. This strategy encourages the growth of imaginative ability based on the identification of feelings associated with sight and touch. For example, when Yu received dental treatment, he recognised that he initially saw the dentist's tools before he felt his tooth being worked on. Thus, he compared this scenario to a situation where a martyr is fighting against an invasion: "following the example of a martyr facing a destined calamity... don't know where the tongue can take refuge" [1] (p. 190).

Sixth, students should train their senses of hearing and touch in tandem. This strategy encourages using the imagination to personify subjects with feelings inspired by hearing and touch. For example, when the wind blows over the skin, the sense of touch is engaged, and when the wind makes a sound, the sense of hearing is engaged. Yu once reflected on how a blowing wind affected his hearing and sense of touch. He compared the sound of leaves rustling in the wind to the sounds a person makes while sick: "the wind is panting and the tree is coughing" [1] (pp. 226-227). Thus, this example shows how the sense of touch is incorporated along with the sense of hearing.

Seventh, students should train their senses of sight, hearing, and touch at the same time. This strategy is all about integrating feelings based on sight, hearing, and touch with literary descriptions in order to personify a subject. For example, while on a skiing trip, Yu described the extensive view of white snow he witnessed with his sense of sight, the bluster of the ice-cold wind he heard based on his sense of hearing, and the physical impact the situation had on his ribs based on his sense of touch as follows: "the white from thousands of mountains swatted my eyes altogether/the ice-cold blustering wind cut my ribs with a saw" [1] (p. 28).

Eighth, students should train their senses of sight, smell, and taste in tandem. This strategy focuses on integrating feelings based on sight, smell, and taste to create impactful personifications. For example, Yu compared the shape and fragrance of a fruit to the figure and odour of a person. In this case, the description of shape was associated with his sense of sight, the description of fragrance was associated with his sense of smell, and the act of biting the fruit was associated with his sense of taste. All of these details work together to yield an impactful case of personification about a mango that "was just taken out of the refrigerator/the body scent assailing the nostrils was so attractive/there was also this crimson and well-rounded figure/biting it on the fullest spot" [1] (pp. 149-150).

In language education concerning personification, using innovative terms is yet another valuable way of capturing the audience's attention and making a deep impression. Thus, teaching students to build rich vocabularies is a key technique in improving their personification abilities and can make their writing more humorous. Using fresh or unexpected terms in place of old, common ones can open people's eyes so that they have more fun while reading and are more receptive to the points being made. Yu was very good at using this technique.

According to the analysis, the creative concepts used to develop fresh terms can be broadly categorised into five groups, namely, colours, time, symbols, shapes, and characteristics. These general concepts can be applied in different combinations within a given sentence. The following are some examples from $\mathrm{Yu}$ that serve as a good introduction for students learning to use this technique: (1) After discovering that house lizards usually move about on their own, Yu considered their loner characteristics and the grey colour of their bodies before using the phrase "a grey loner" to mean "a house lizard" [1] (p. 144). (2) Using the concept of colour alone, Yu described ducks with white feathers as "men in white dress" [1] (p. 90). (3) Inspired by the concept of time, Yu described a cricket jumping into a house as "a new guest" [1] (p. 120). (4) Again, reflecting on the concept of time and how quickly dusk seems to arrive, Yu thought of it as being smuggled. Thus, he described dusk as 'the stowaway' and the night as "the black gang" [1] (p. 62). (5) Relying on symbolism, Yu decided that a large chimney with dark smoke coming out of it can be likened to a "heavy smoker with [a] strong addiction to cigarettes" [1] (p. 226). (6) After seeing a snail with its shell intact moving very slowly, Yu associated the scene with the image of a soldier crawling around with his heavy equipment. 
Thus, Yu replaced "the snail" as a subject with "the trooper" based on the categories of characteristics and shapes [1] (p. 130). (7) Having observed cockroaches and feeling that their timing made them seem like people sneaking around, Yu replaced "the cockroaches" with "a smuggling ring", thus using the categories of characteristics, time, and symbols [1] (p. 121).

However, it should be noted that the use of innovative terms is only one fundamental concept of personification. A key factor behind the success of such a comparison is the logical connection the writer makes between the fresh terms being included and the scenarios in which they are used. In this regard, the writer's intention when considering the properties of the subject for personification and the most appropriate terms to express this intent are what yield a successful design or case of personification. A notable example for students in language education comes from Yu's description of the wind as a hermit. Yu makes a rich story with this case of personification by saying, "There is $a$ hermit in this mountain region/when he shows up, his sleeves... float in the air gracefully/listen to that happy hermit at this moment/fiddling with everything along the way" [1] (p. 66, italics added). Recognising that the wind, as an invisible subject, can be hard to relate to, Yu settled on likening the wind to a hermit based on their shared characteristics. A more thorough analysis shows that Yu compared the motion of the wind to the happy mood of a person and chose to describe the scene of leaves rustling in the wind with the phrases "his sleeves... float in the air gracefully" and "fiddling with everything along the way" [1] (p. 66). Yu's design with this act of personification creates a clear-cut image of a person that matches the characteristics associated with his hermit character. Taken as a whole, the examples in this section demonstrate how innovative terms can be developed using the senses and the writer's feelings associated with them. Students who are taught to hone their imaginations by concentrating on making connections between their senses, feelings, and vocabularies will be able to provide readers with fresh and novel experiences when using personification, and Yu's work provides many illustrative examples of how one consummate poet used personification effectively to express his great sense of humour.

Moreover, in language education, students should be taught affection shifting and association as two methods of literary creation through personification. These two terms translate to two different orientations, namely, the active expression of affection and the passive reflection on a given scene. There can be overlap in carrying out either act, and both affection shifting and association extend from considerations of affection. It is worth noting how affection shifting or affection association is achieved since it is impossible to cultivate the true energy of creation without such an orientation. Therefore, before applying the energy of creation to personification, students must cultivate their minds to hold an affection of care. Once established, this affection of care can be shifted or reflected to one's surroundings or other things on earth. Although this principle may be a difficult one to explain to students, it can be likened to shooting in basketball. One must have the ball in hand before attempting a shot at the basket. Likewise, the care students have for their lives, environments, and all things on earth serves as the motivating power that fuels the energy of creation in personification.

A successful description using personification comes from the use of literary techniques to create vivid expressions and fresh images. That is, a case of personification is more impactful when the images being conjured up are more vivid and true to life. The goal of personification is to create a fresh impression in readers' minds that allows them to immerse themselves in the literary creation and helps them feel as if they themselves are experiencing what is being described. The researcher suggests that personification is especially useful when applied to descriptions of details or changes that occur in a short moment since in these situations the personification can help enhance the effect of such quick observations on readers. The function of language education is to use expressive tools such as personification to start positive conversations about the philosophy of life and enlighten people about how to create better, more enriching lives for themselves. That is why cultivating an affection of care is a core part of teaching personification, which in itself represents one sustainable tool that supports the spirit of language education. 
Taking the findings of this study as a whole, it is suggested that the examples of Yu's poetry that have been analysed and featured would make good references for teaching personification in language education. Furthermore, the analysis has yielded many different techniques and methods students can use to frame their thinking in a way that facilitates the creation of high-quality figures of speech. To be specific, this study has presented four main takeaways for teaching personification: (1) The various definitions of personification presented in the introduction section can be adapted to help students gain a more comprehensive understanding of what it means to personify something. (2) The study's findings regarding Yu's use of personification can help students clearly grasp the key ideas and literary approaches underpinning an act of personification. (3) The conclusions concerning Yu's poetry and the examples of his work presented for analysis can serve as references for students to model their own works of personification off of. (4) The creation models for personification can provide scaffolding for students as they hone their critical thinking skills to think of creative and innovative ways to use the figure of speech. It should be noted that these four takeaways complement one another and all centre on supporting student learning in language education. Therefore, with the ample amount of analysis and number of personification techniques presented throughout this study, it is expected that students will be better able to implement personification in their own writing within and beyond language education and that this writing will yield rich artistic expression in a sustainable manner, which in turn will allow cultural literacy to thrive.

Funding: This research received no external funding.

Conflicts of Interest: The author declares no conflict of interest.

\section{References}

1. Chen, X.H. (Ed.) Collection of Humorous Free Verses by Kwang-Chung Yu; Commonwealth Publishing Group: Taipei, Taiwan, 2008; ISBN 978-986-216-216-3.

2. Gu, Y.Q. On Yu Guangzhong's modern poems. J. Sch. Chin. Lang. Cult. Nanjing Norm. Univ. 2009, 2, 57-61.

3. $\mathrm{Wu}, \mathrm{Z} . \mathrm{W}$. A textual reading of Yu Guangzhong's prose: 'Listening to chill rain'. J. Changzhou Inst. Technol. (Soc. Sci. Ed.) 2011, 29, 15-19.

4. Chen, C.Y. Refugee and poet-sage: Images of $\mathrm{Du} F u$ in Yu Guangzhong's poems. J. Hainan Norm. Univ. (Soc. Sci.) 2010, 23, 77-83.

5. Chou, H.P. The longitudinal heritage: The heritage and originality in 'Lee Po Trilogy' authored by Yu Kuang-Chung. J. Pingdingshan Univ. 2007, 22, 95-103.

6. Chang, C.C. Yu Kwang-Chung myth mythopoetry poetic metamorphosis. J. Chin. Lit. Chin. Cult. Univ. 2010, 21, 85-107. [CrossRef]

7. Ting, H.H. The classic inheritance and initiation of Yu Guangzhong's poetry. Kaohsiung Norm. Univ. J. Chin. Lit. 2013, 17, 31-59.

8. Wei, Y. The classical pursuit in new Chinese poetry: A case study of Yu Guang-zhong and Luo Fu's poetic art. J. Yunnan Univ. (Soc. Sci. Ed.) 2008, 7, 73-84.

9. Gao, D.W. Rhetorical modes of thought from the comparative perspective: Yu Kuang-Chung on the Europeanization of modern Chinese. Bull. Dep. Chin. Lit. Natl. Chengchi Univ. 2014, 22, 131-157.

10. $\mathrm{Xu}, \mathrm{X}$. Yu Guangzhong's literature writing and modern painting. Taiwwan Res. Q. 2008, 2, 10-15.

11. Shiu, W.W. Yu Kuang-Chung's influence of multi-area literary communication in 1970s. Bull. Taiwan. Lit. 2011, 19, 163-190.

12. Zeng, W. Yu Guangzhong's views on translation. J. Wuhan Univ. Sci. Technol. (Soc. Sci. Ed.) 2005, 7, 87-89.

13. Li, X. Yu Kuang-Chung's drama translation practice: A case study of the importance of being earnest. J. Huaihai Inst. Technol. (Humanit. Soc. Sci. Ed.) 2010, 8, 96-98.

14. Wang, L. Yu Guangzhong's domesticating strategy of play translation. J. Chaohu Coll. 2010, 12, 108-112.

15. Gu, Y. The modern interpretation of the meanings of the classic term 'rain' in Yu Guangzhong's works. Mod. Lit. Mag. 2008, 2, 121-123.

16. Gu, Y. Yu Guangzhong's inheritance and richness of the sensibility of 'rain' in classical literature. Sichuan Univ. Arts Sci. J. 2009, 19, 60-62. 
17. Liu, Z.Z. The lyrical issue of Yu Kwang-Chung's poetry. Bull. Dep. Chin. Lit. Natl. Taiwan Univ. 2016, 54, 223-263.

18. Huang, W.L. Yu Guangzhong as a Xiangtu (native region) poet. Contemp. Poet. 2006, 2, 31-47. [CrossRef]

19. Liu, C.W. Initial research on the nostalgia in modern poetry of Yu Guang-Zhong. J. Natl. United Univ. 2012, 9, 143-156. [CrossRef]

20. Lai, W.Y. Tug-of-war with lamentations of spring: A study of Yu Kwang-Chung's time consciousness. J. Xuzhou Norm. Univ. (Philos. Soc. Sci. Ed.) 2008, 34, 16-18.

21. Liang, X.M. Poems by Yu Guangzhong under the meaning of communication studies. Jianghan Trib. 2005, 3, 100-104.

22. Up Media. Kwang-Chung Yu Passed Away: A Legendary Poet. Available online: http:/ /www.upmedia. $\mathrm{mg} /$ news_info.php?SerialNo=31174 (accessed on 8 January 2018).

23. Chen, J.W. The character writing in Yu Huan's Weilüe: A study in the range of royal narrative. J. Lang. Lit. Stud. 2017, 31, 43-74.

24. Chiang, L.H. Analysis of Meng Haoran how to use cultural landscape to write the poem, 'Rafting in Ruo-Ye River'. Stud. Sinol. 2017, 39, 53-78. [CrossRef]

25. Shen, F.Y. Literary works and creative writing activities of talented women in the Han, the Wei, and the Six Dynasties: An investigation based on 'Groups'. Bull. Dep. Chin. Lit. Natl. Taiwan Univ. 2017, 58, 51-104. [CrossRef]

26. Tsai, Y.C. The concept of landscape in literary thought and its relation to that of nature. Tsing Hua J. Chin. Lit. 2017, 18, 101-147.

27. Wang, H.W. On Jiang Chunlin's historical Qi under the regime of Xianfeng emperor. J. Chin. Lit. Provid. Univ. 2017, 12, 19-54.

28. Huang, W.S. The connotations of life education in 'Shi Li Yu Yao'. J. Natl. Taipei Coll. Bus. 2018, 33, 61-84.

29. Fan, Y.J. Shrouded literary imagination? A study based on the knowledge transmission records and the writing modes of the Chi-Ya. Bull. Dep. Chin. Lit. Natl. Chengchi Univ. 2017, 28, 69-101.

30. Chang, J.H. Mental space theory and the metaphors of refusing official positions in the Fables of Zhuangzi. J. Taiwan Lang. Lit. 2017, 12, 161-185. [CrossRef]

31. Lee, M.C. Observation on the monologue in life: Chi-Deng-Sheng's native from 'Return to the River'. J. Chin. Stud. 2017, 24, 85-106.

32. Liao, P.Y. Narrative space-time in the 'Assassin'. Dong Hwa J. Chin. Stud. 2017, 26, 169-207.

33. Shih, H.F. The settling of ideals and self: An observation from the space experience in Chen Lie's prose. Tsing Hua J. Chin. Stud. 2017, 47, 591-619. [CrossRef]

34. Chao, H.Y. Space transfer and time clues: A study of Yi-Zun Chu's travel verses. Dong Hwa J. Stud. Chin. Lit. Philos. 2018, 5, 37-78.

35. Kao, C.Y. Emotional respond form's theoretical paradigm in core theory of 'The Literature Mind Elaborations'. Chin. J. 2017, 35, 55-74.

36. Lo, Y.C. A new perspective of Da Zhen's philosophy based on ancient bamboo slips and Western virtue ethics. Soochow J. Chin. Stud. 2017, 34, 145-176.

37. Ting, W.J. A study of Bai Ciou's poetic theory taking the discussion of 'Modern Poetry as a Spindle'. Contemp. Poet. 2016, 11, 2-35.

38. Chen, M.C. Can Xue's fictional aesthetic: Its route and concerns. Tsing Hua J. Chin. Stud. 2018, 48, 73-112. [CrossRef]

39. Lin, C.Y. 'With the Skills to Take the Seats': A Discourse of Ruan Dacheng, the 'Composer' in The Peach Blossom Fan, and the Drama. J. Theater Stud. 2018, 21, 1-33. [CrossRef]

40. Teng, M.C. Perspective transfer and style in Chinese translations of Yukio Mishima's 'Shiosai'. Compil. Transl. Rev. 2017, 10, 1-39.

41. Chung, M.L. The propaganda content and creative words on wall-scribed poems of Huang, Ting-Chien. J. Appl. Chin. 2016, 18, P37-P78.

42. Yen, Y.S. (Ed.) Time English-English and English-Chinese Dictionary; Mass Publication: Taipei, Taiwan, 2001.

43. Yen, Y.S. (Ed.) Eurasia's Modern Practical English-English English-Chinese Dictionary; Chuang-Yuan Publication: Taipei, Taiwan, 1979.

44. Mayor, M. Macmillan English-Chinese Dictionary; Bookman Books: Taipei, Taiwan, 2013. 
45. Pearson Education. Longman Dictionary of Contemporary English, 4th ed.; Pearson Education Asia Limited: Hong Kong, China, 2009.

46. Li, P.Y. The American Heritage Dictionary for Learners of English; Foreign Language Teaching and Research Press: Beijing, China, 2006.

47. Thompson, D. Oxford English-Chinese Dictionary; Warmth Co.: Taipei, Taiwan, 2013.

48. Pearson Education. Longman Dictionary of Contemporary English (English-Chinese), 5th ed.; Pearson Education Asia Limited: Hong Kong, China, 2013.

49. Waite, M. Little Oxford English-Chinese Dictionary; Warmth Co.: Taipei, Taiwan, 2009.

50. Chang, D.Z. Modern English Dictionary; Wunan Books: Taipei, Taiwan, 1991.

51. Xue, Y. International Dictionary (English through English) English-Chinese (Based on Webster's New International Dictionary, 2nd ed.; China Books: Taipei, Taiwan, 1997.

52. Tsai, C.S.; Tsao, F.F.; Chang, W.C.; Chen, X.Z.; Liu, S.H.; Li, M.Z.; Wang, H.C. Advanced English-English English-Chinese Dictionary; Wen Shin Bookstore: Taipei, Taiwan, 2006.

53. The Reader's Digest Association. A New Theasurus of Synonyms and Antonyms in Dictionary Form; Shanghai Printing Press: Hong Kong, China, 1977.

54. Random House, Inc. Random House Webster's Unabridged Dictionary; Random House: New York, NY, USA, 2001.

55. Federal Street. Webster's New Explorer Dictionary; Federal Street Press: Darien, CT, USA, 1999.

56. Spears, R.A. NTC'S American English Learner's Dictionary; NTC/CONTEMPORY Publishing Group: Chicago, IL, USA, 1998.

57. Harcourt, Brace \& World, Inc. The Harcourt Brace Intermediate Dictionary; Harcourt, Brace \& World, Inc.: Orlando, FL, USA, 1968.

58. Funk \& Wagnalls, Inc. Funk \& Wagnalls Standard Desk Dictionary; Funk \& Wagnalls, Inc.: New York, NY, USA, 1986.

59. Morris, W. The New American Heritage Onary of the English Language (Revised Taiwan Edition); Mei Ya Publications, Inc.: Taipei, Taiwan, 1969; reprinted.

60. Huang, Q.X. Rhetoric, 3rd ed.; Sanmin: Taipei, Taiwan, 2005.

61. Chen, Z.Z. Rhetoric, 2nd ed.; Wunan: Taipei, Taiwan, 2009.

62. Wu, Z.G. Rhetoric, 3rd ed.; Fu Wen: Kaohsiung, Taiwan, 2000.

63. Huang, L.Z. Practical Rhetoric; Guojia: Taipei, Taiwan, 1999.

64. Shen, Q. Rhetoric, rev. ed.; Open University: New Taipei, Taiwan, 1995.

65. Dong, J.T. Rhetorical Analysis; Wen Shi Zhe: Taipei, Taiwan, 1994.

66. Wang, W.K. Educational Research Methodology; Wunan: Taipei, Taiwan, 2001.

67. Huang, K.H.; Jian, M.F. Educational Research Methodology; Shtabook: Taipei, Taiwan, 1991.

68. Yang, K.S.; Wen, C.I.; Wu, C.X. Social and Behavioral Science Research Methodology; Tung Hua: Taipei, Taiwan, 1985.

69. Chang, S.S. Research Methods; Tsang-Hai: Taichung, Taiwan, 2001.

70. Xi, R.C. Social and Behavioral Science Research Methods; Wunan: Taipei, Taiwan, 1997.

(C) 2018 by the author. Licensee MDPI, Basel, Switzerland. This article is an open access article distributed under the terms and conditions of the Creative Commons Attribution (CC BY) license (http:/ / creativecommons.org/licenses/by/4.0/). 